\title{
Marginal Discrepancy of Single Implant-Supported Metal Copings Fabricated by Various CAD/CAM and Conventional Techniques Using Different Materials
}

\author{
Safoura Ghodsi ${ }^{1} \quad$ Marzieh Alikhasi ${ }^{1} \quad$ Nika Soltani ${ }^{2}$ \\ ${ }^{1}$ Department of Prosthodontics, School of Dentistry, Dental \\ Research Center, Dentistry Research Institute, Tehran University of \\ Medical Sciences, Tehran, Iran \\ ${ }^{2}$ Department of Prosthodontics, School of Dentistry, Tehran \\ University of Medical Sciences, Tehran, Iran
}

\begin{abstract}
Address for correspondence Nika Soltani, DDS, Department of Prosthodontics, School of Dentistry, Tehran University of Medical Sciences, North Karegar St.,1613679145, Tehran, Iran (e-mail: soltaninika@yahoo.com).
\end{abstract}

Eur J Dent 2019;13:563-568

\begin{abstract}
Objective Framework patterns can be formed using various materials such as wax, acrylic resin, or composite. Frameworks can be fabricated using either conventional or computerized techniques, using additive or subtractive method. This study aimed to compare the marginal adaptation of metal copings fabricated by two computerized technologies (milling and rapid prototyping) and additive conventional methods using different materials.

Materials and Methods Seventy-two fixture analogs were mounted vertically in acrylic resin. One-piece abutments with $5.5 \mathrm{~mm}$ in length and 6 degrees of convergence were secured into the analogs. The experimental frameworks were fabricated using either subtractive CAD/CAM milling (by wax, soft or hard metal), additive rapid prototyping (by wax), or conventional pattern fabrication (by wax [control] or acrylic resin). Wax and acrylic resin patterns were casted in $\mathrm{Ni}-\mathrm{Cr}$ alloy. Marginal discrepancy was measured in 12 points by video measuring machine.

Statistical Analysis One-way ANOVA and posthoc tests were used to detect any significant difference among the groups at $\alpha=0.05$.

Keywords

- dental implants

- dental marginal adaptation

- dental materials

- computer-aided design

- metal ceramic alloys

Results There was a statistically significant difference among the marginal discrepancy of six groups $(p=0.018)$. The Tukey test indicated a significant difference between $C A D /$ milling of soft metal and conventional wax pattern groups $(p=0.011)$; a significant difference was also reported between $C A D /$ milling of wax patterns and control group $(p=0.046)$.

Conclusions Frameworks fabricated by conventional wax-up showed the largest marginal gaps, while the marginal gap created by frameworks made of soft metal $\mathrm{CAD} /$ milling were the smallest. In addition, frameworks fabricated by rapid prototyping showed clinically acceptable adaptations.
\end{abstract}

\section{Introduction}

Marginal adaptation is one of the most important factors in the long-term success of implant restorations. An accurate adaptation between implant abutment and restoration is necessary for clinical success and prosthesis durability. ${ }^{1}$

DOI https://doi.org/

10.1055/s-0039-1700364

ISSN 1305-7456.
Lack of marginal adaptation may result in several biological and mechanical problems such as pain, marginal bone loss, plaque accumulation, increase in gingival index and periodontal pocket depth, abutment loosening, osseointegration loss, and even implant failure. ${ }^{2-4}$ The marginal adaptation of cement-retained implant restorations can be affected by 
different factors including impression materials and techniques, restoration type, fabrication procedure, material used, technician expertise, cement type, and cementation process. ${ }^{5-9}$ Various techniques have been suggested for measuring marginal discrepancy, and one of the most common non-aggressive techniques is direct view; ${ }^{10-13}$ other methods include impression replica technique, ${ }^{11}$ cross-sectioning technique, ${ }^{14}$ contact scanner technique, ${ }^{15}$ and laser videography. ${ }^{16}$ One of the acceptable processes is application of video measuring machine (VMM), which relies on non-contact video measurement of high resolution images. This system provides an inexpensive, accurate, and fast procedure to monitor critical dimensions of object without scarifying the specimen. ${ }^{17}$

The framework pattern of a restoration can be fabricated by either conventional, computerized, or a combination techniques using a variety of materials such as wax, composite, acrylic resin, and even directly by metal. ${ }^{18,19}$ After the introduction of computerized systems-for example, computer assisted design/milling (CAD/milling) and computer assisted design/rapid prototyping (CAD/RP)-fabrication of higher quality restorations became promising without the limitations of conventional methods. ${ }^{19-21}$ Computer-assisted procedures omitted several steps in fabrication flow, ${ }^{22}$ improved procedural reliability, ${ }^{23}$ facilitated using new materials not applicable in conventional methods, reduced labor and cost, improved quality control, and increased production rate. ${ }^{19,24}$ However, transformation of point angles to smooth surfaces, and the limitation of finite resolution, leading to round edges are reported as disadvantages. ${ }^{22}$

Recent studies have reported contradictory results for the marginal discrepancy of restorations made by different methods..$^{23,25-36}$ Several studies reported greater marginal discrepancies in restorations fabricated by the CAD/CAM systems, ${ }^{23,25-29}$ while others showed greater values in restorations made by conventional methods, ${ }^{30-33}$ or even reported no significant differences ${ }^{34}$ (-Table 1). The present study aimed to compare the marginal discrepancy of single implant-supported frameworks fabricated by different materials, using additive conventional/computerized and subtractive computerized methods. The null hypothesis was that there will be no significant differences between marginal adaptation of specimens made by different methods.

\section{Materials and Methods}

The sample size of 12 for each group was determined using a power analysis to provide statistical significance $(\mathrm{a}=0.05)$ at 80\% power. Seventy-two implant analogues (Fixture Laboratory analogue, Ufit Dental implant system, South Korea) were mounted vertically in acrylic resin (Acrylic resin for patterns, GC America INC, Alsip, IL, USA). Impression coping was used on a dental surveyor (Ney Dental International, Bloomfield, CT, United State) as a guide to ensure the parallel mounting of each specimen. One-piece abutments (Solid abutment; Ufit Dental implant system, South Korea) of $5.5 \mathrm{~mm}$ length and 6 degrees of convergence were secured in the fixture analogues. Experimental groups $(n=12)$ were prepared as follows by the same expert technician to prevent interoperator bias (descriptive chart of prepared groups has been shown in - Fig. 1). The conventional wax group was considered as the control group.

\section{CAD/Milling Specimens ( 3 Groups)}

Thirty-six abutments were sprayed (Scanspray; Renfertp GmbH, Hilzingen, Germany) and scanned by a laser scanner (3Shape D810, 3Shape, Copenhagen, Denmark). Data was transmitted to a software program (3Shape's CAD Design software, 3Shape, Copenhagen, Denmark). The cement space was set at $30 \mu$ starting $0.5 \mathrm{~mm}$ from the margin; the anatomic patterns were designed and milled using three different materials: wax, soft, and hard Cr-Co metal. Wax patterns (Yeti,; Dentalproduct GmbH, Engen, Germany) were milled by a milling machine (CORiTEC 350i; Imes-icore, Eiterfeld, Germany) using a T35-drill with a $2 \mathrm{~mm}$ diameter, invested in phosphate-bonded investments (Z4-C\&B investment; Neirynck \& Vogt, Schelle, Belgium), and cast by $\mathrm{Ni}-\mathrm{Cr}$ alloy in a casting machine (Nautilus CC plus; Bego, Bremen, Germany). Soft metal Cr-Co patterns (Ceramill Sintron; Amann Girrbach AG, Austria) were milled by Amann Girrbach CAM system (Ceramill motion 2; Amann Girrbach AG, Austria) using drill no. 760605 with 2.5 mm diameter, and sintered at $1300^{\circ} \mathrm{C}$ in vacuum oven (Argovent; Amann Girrbach AG, Austria). Hard metal Cr-Co blocks were milled in a milling machine (CORiTEC 450i; Imes-icore GmbH, Eiterfeld, Germany) using a T40-drill with a $2.5 \mathrm{~mm}$ diameter. A silicone index was made from the first pattern to be used for standardization of the thickness/contour of conventional wax and acrylic resin patterns.

\section{CAD/RP Specimens (1 Group)}

After scanning the abutments and designing the patterns in the same way as $\mathrm{CAD} /$ milling models, wax patterns ( $n=12$ ) were prepared using a 3D printer (R66PLUS, Solidscape Inc, Merrimack, NH) by an Inkjet base system. The copings were invested in phosphate-bonded investments (Z4-C\&B investment [and casted in Ni-Cr alloy (Nautilus CC plus]).

\section{Conventional Specimens (2 Groups)}

For wax patterns (control group), two layers of spacer (PICO-FIT; Renfert GmbH, Hilzingen, Germany) were applied to the abutments starting $0.5 \mathrm{~mm}$ from the margin, with a total thickness of approximately $30 \mu \mathrm{m}$. After drying, a layer of separating medium (Picosep; Renfert GmbH, Hilzingen, Germany) was applied. The wax patterns were formed by inlay wax (GEO classic; Renfert GmbH, Hilzingen, Germany), and based on silicone index obtained from the first $\mathrm{CAD} /$ milling wax pattern. The marginal wax was reflowed before investing.

For acrylic patterns, two layers of spacer (Bredent; XPdent, Miami, United States) were applied on abutments starting $0.5 \mathrm{~mm}$ from the margin for an approximate total thickness of $30 \mu \mathrm{m}$. Acrylic resin patterns (GC Corp; Tokyo, Japan) were formed based on the same silicone index. The wax and acrylic copings were invested in phosphate-bonded investments (Z4-C\&B investment) and casted in $\mathrm{Ni}-\mathrm{Cr}$ alloy (Nautilus CC plus). Casting sprues were separated from the models and the 
Table 1 A summary of related studies

\begin{tabular}{|c|c|c|c|c|}
\hline Study & Measurement method & Material & Fabrication method & $\begin{array}{l}\text { Marginal discrepancy } \\
(\mu \mathrm{m})\end{array}$ \\
\hline \multirow[t]{3}{*}{ Tan et $\mathrm{al}^{23}$} & \multirow[t]{3}{*}{ Direct view technique } & Titanium blocks & CAD/CAM & $79.43 \pm 25.46$ \\
\hline & & \multirow[t]{2}{*}{ High noble } & Conventional wax-up/CAM & $73.12 \pm 24.15$ \\
\hline & & & Conventional wax-up, casting & $23.91 \pm 9.80$ \\
\hline \multirow[t]{2}{*}{ Farjood et al ${ }^{25}$} & \multirow{2}{*}{$\begin{array}{l}\text { Cross-sectioning, digital } \\
\text { microscope }\end{array}$} & \multirow[t]{2}{*}{ Wax } & CAD/RP wax/casting & $89.8 \pm 8.3$ \\
\hline & & & Conventional wax-up, casting & $69.5 \pm 15.6$ \\
\hline \multirow[t]{2}{*}{ Han et $\mathrm{al}^{26}$} & \multirow[t]{2}{*}{ Cross-sectional } & \multirow[t]{2}{*}{$\begin{array}{l}\text { Wax } \\
\text { titanium blocks }\end{array}$} & Conventional wax-up, casting & $\begin{array}{l}\text { Shoulder: } 55.2(20.0) \\
\text { chamfer: } 52.2(14.2) \\
\text { Knife edge: } 76.1(9.4)\end{array}$ \\
\hline & & & CAD/CAM hard metal & $\begin{array}{l}\text { Shoulder: } 67.0(14.1) \\
\text { chamfer: } 59.8(14.9) \\
\text { knife edge: } 80.7(10.4)\end{array}$ \\
\hline \multirow[t]{2}{*}{ Vojdani et al } & \multirow{2}{*}{$\begin{array}{l}\text { Cross-sectioning, digital } \\
\text { microscope }\end{array}$} & \multirow[t]{2}{*}{ Wax } & CAD/CAM wax, casting & $157.37 \pm 20.63$ \\
\hline & & & Conventional wax-up, casting & $69.54 \pm 15.60$ \\
\hline \multirow[t]{3}{*}{ Kim et al ${ }^{29}$} & \multirow[t]{3}{*}{ Micro CT imaging } & \multirow[t]{3}{*}{$\mathrm{Cr}-\mathrm{Co}$} & Conventional wax-up, casting & $70.4 \pm 12.0$ \\
\hline & & & CAD/CAM milling & $123.5 \pm 32.1$ \\
\hline & & & Selective laser melting & $98.7 \pm 26.9$ \\
\hline \multirow[t]{4}{*}{ Nejatidanesh et al ${ }^{30}$} & \multirow[t]{4}{*}{ Replica technique } & IPS e.max CAD & \multirow[t]{2}{*}{ CAD/CAM } & $32.02 \pm 10.38$ \\
\hline & & Zirconia & & $34.26 \pm 11.41$ \\
\hline & & IPS e.max press & Conventional wax-up, press & $74.99 \pm 24.51$ \\
\hline & & Base metal & Conventional wax-up, casting & $59.19 \pm 17.81$ \\
\hline \multirow[t]{2}{*}{ Ghodsi et al ${ }^{31}$} & \multirow[t]{2}{*}{ Replica technique } & Wax & \multirow[t]{2}{*}{ CAD/CAM } & $18.0 \pm 1.0$ \\
\hline & & Cr-Co blocks & & $176.07 \pm 53.54$ \\
\hline \multirow[t]{2}{*}{$\mathrm{Ng}$ et $\mathrm{al}^{32}$} & \multirow[t]{2}{*}{ Direct view technique } & \multirow{2}{*}{$\begin{array}{l}\text { Lithium } \\
\text { disilicate }\end{array}$} & Conventional wax-up, pressing & $74 \pm 47$ \\
\hline & & & CAD/CAM & $48 \pm 25$ \\
\hline \multirow[t]{2}{*}{ Xu et $a^{33}$} & \multirow[t]{2}{*}{ Replica technique } & \multirow[t]{2}{*}{$\mathrm{Co}-\mathrm{Cr}$} & Conventional wax-up, casting & 170.19 \\
\hline & & & Selective laser melting & 102.86 \\
\hline \multirow[t]{2}{*}{ Lalande et $\mathrm{al}^{34}$} & \multirow[t]{2}{*}{ Sectioning } & \multirow{2}{*}{$\begin{array}{l}\text { Complete gold } \\
\text { crown }\end{array}$} & Conventional wax-up, casting & $52 \pm 31$ \\
\hline & & & CAD/CAM acrylic, casting & $45 \pm 27$ \\
\hline \multirow[t]{3}{*}{ Nesse et $\mathrm{al}^{35}$} & Replica technique & $\mathrm{Co}-\mathrm{Cr}$ & Conventional wax-up, casting & Good marginal fit \\
\hline & & & CAD/CAM milling & Best marginal fit \\
\hline & & & Selective laser melting & Poor marginal fit \\
\hline Afify et $\mathrm{al}^{36}$ & Direct view technique & Wax & CAD/CAM milling + casting & $35.5 \pm 18.5$ \\
\hline & & Noble alloy & CAD CAM milling & $18.7 \pm 20.4$ \\
\hline & & Noble alloy & Direct laser sintering & $22.8 \pm 13.5$ \\
\hline
\end{tabular}

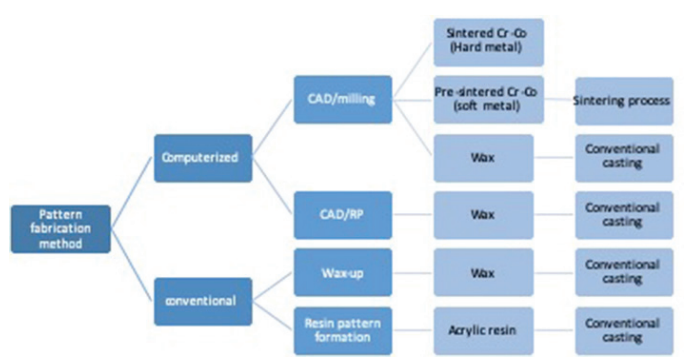

Fig. 1 Descriptive chart of specimens.

internal surfaces of the copings were sandblasted (Basic master; Renfert $\mathrm{GmbH}$, Hilzingen, Germany) by $\mathrm{Al}_{2} \mathrm{O}_{3}$ particles (50 $\mu \mathrm{m}$ ) under 0.3 MPa pressure.
The internal surface of each coping was evaluated by a binocular loop (HEINE HR-C 2.5x, HEINE, Herrsching, Germany) and visible macro nodules were removed with a tungsten carbide bur (H71EF; Brasseler GmbH.KG, Komet, Siegel, Germany). Invisible nodules, irregularities, or pressure points were determined using a disclosing agent (Occlude indicator spray, Pascal International Inc, Seattle, Washington), and adjusted by round bur (Teezkavan; Tehran, Iran) up to the point that complete siting was confirmed by two prosthodontists blinded about materials/methods used for fabrication of the specimen. The copings were stabilized on abutments by pressure-indicating paste (GC fit checker, GC Corp, Tokyo, Japan), and the marginal discrepancy was measured in 12 points (middle of buccal, mesial, distal, and lingual surfaces, and two points between 
each adjacent pair) marked on acrylic base. Marginal discrepancy was measured by a noncontact video measuring machine (AV350 + CNC; Starrett, Galileo Vision System, Birmingham, England) with Heidenhain 0.1 micron resolution scale and 3-axis stage with $350 \times 350 \times 200 \mathrm{~mm}$ XYZ travel ( - Fig. 2). (SPSS Inc; Chicago, IL, United States) was used for statistical analysis. The discrepancy values were reported in millimeter scale and analyzed by one-way ANOVA and Tukey tests ( $p<0.05)$.

\section{Results}

The (mean \pm SD) for the marginal discrepancy of implantsupported frameworks fabricated from $\mathrm{CAD} /$ milling hard metal, $\mathrm{CAD} /$ milling soft metal, $\mathrm{CAD} /$ milling wax patterns, $\mathrm{CAD} / \mathrm{RP}$ wax patterns, conventional wax patterns, and conventional acrylic pattern were $0.12 \pm 0.07 \mathrm{~mm}, 0.09 \pm 0.06 \mathrm{~mm}$, $0.11 \pm 0.06 \mathrm{~mm}, 0.11 \pm 0.04 \mathrm{~mm}, 0.20 \pm 0.12 \mathrm{~mm}$, and $0.12 \pm$ $0.07 \mathrm{~mm}$ respectively (-Fig. $\mathbf{3}$, - Table 2 ). According to the one-way ANOVA test, there was a statistically significant difference among the marginal discrepancy in six groups $(p=0.018)$. The Tukey test indicated a significant difference

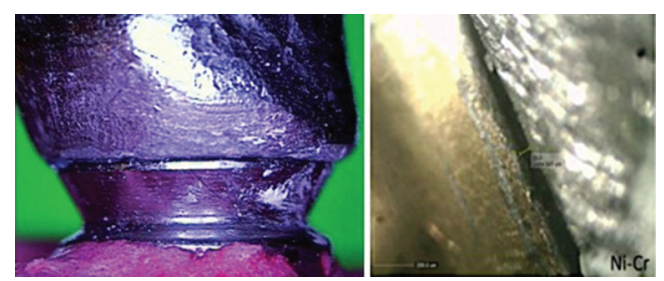

Fig. 2 VMM measurement of casted specimen. VMM, video measuring machine.

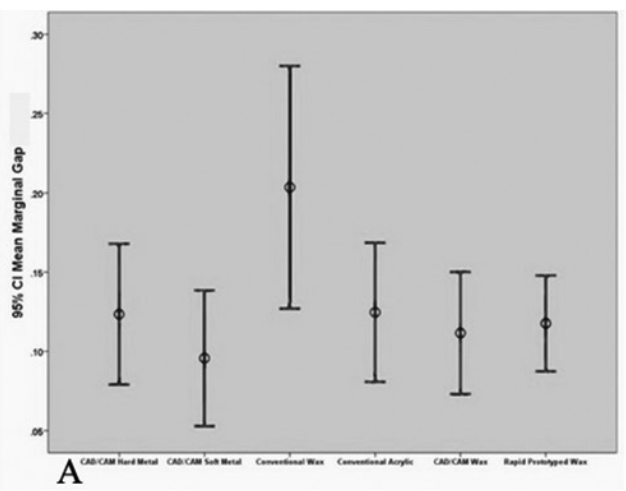

between $\mathrm{CAD} /$ milling soft metal and control group (conventional wax patterns) ( $p=0.011)$; a significant difference was also reported between $\mathrm{CAD} / \mathrm{milling}$ wax patterns and control group $(p=0.046)$.

\section{Discussion}

The present study was conducted to compare the marginal discrepancies in single-unit, implant-supported frameworks prepared by different methods/materials. The investigated groups were $\mathrm{CAD} / \mathrm{milling}$ hard metal, $\mathrm{CAD} / \mathrm{milling}$ soft metal, and conventional casting of patterns fabricated by $\mathrm{CAD} /$ milling wax, CAD/RP wax, and conventional handformed wax (control) or acrylic resin. The null hypothesis was rejected as there was significant difference between the specimens formed by different methods. Marginal discrepancy was significantly less in CAD/milling soft metal and $\mathrm{CAD} / \mathrm{milling}$ wax compared with the control group. The sintering shrinkage of pre-sintered metal has been reported in approximately $11 \%$ of cases. ${ }^{37}$ However, the milling system compensates for dimensional change by milling a larger pre-sintered coping; according to the result of the present study, it seems the compensation worked well and the soft metal group showed the least marginal gap $(95.7 \mu \mathrm{m}$ \pm 0.0673 ). Wax pattern fabrication is a time-consuming and labor-intensive step which is highly dependent on technician's skill. It is also claimed that removing wax pattern from a die with shoulder margin can lead to a margin opening of approximately $35 \mu \mathrm{m}$. Moreover, wax color usually makes it difficult to detect small defects in wax patterns. ${ }^{38}$ $\mathrm{CAD} / \mathrm{CAM}$ restorations, on the other hand, reduce the effect of technician's expertise; however, their accuracy still

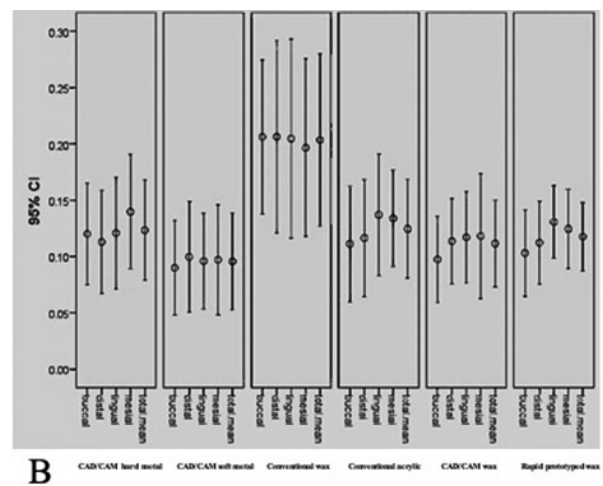

Fig. 3 Mean marginal discrepancy (A) in different groups; (B) separated by different measured points.

Table 2 Descriptive data of different evaluated groups

\begin{tabular}{|l|l|l|l|l|l|}
\hline Specimen & $\boldsymbol{n}$ & Minimum $(\mathbf{m m})$ & Maximum $(\mathbf{m m})$ & Mean $(\mathbf{m m})$ & Std. deviation \\
\hline Conventional wax & 12 & 0.040 & 0.471 & 0.2035 & 0.1204 \\
\hline Conventional acrylic & 12 & 0.050 & 0.273 & 0.1246 & 0.0690 \\
\hline CAD/milling hard metal & 12 & 0.000 & 0.225 & 0.1234 & 0.0698 \\
\hline CAD/milling soft metal & 12 & 0.000 & 0.205 & 0.0957 & 0.0673 \\
\hline CAD/milling wax & 12 & 0.000 & 0.215 & 0.1116 & 0.0605 \\
\hline Rapid prototyped wax & 12 & 0.020 & 0.204 & 0.1176 & 0.0476 \\
\hline
\end{tabular}


depends on the computer software design, milling material, and sintering shrinkage. ${ }^{39,40}$ According to the present study, $\mathrm{CAD} /$ milling wax caused significantly less marginal gap (111.6 $\mu \mathrm{m} \pm 0.0605)$ compared with hand-formed wax pattern group ( $203.5 \mu \mathrm{m} \pm 0.1204)$. All the fabrication methods were made directly on the abutments to eliminate the effect of impression and pouring materials on the obtained results. Therefore, using the same material (wax) and process (conventional casting), the result confirms the significant effect of procedure (CAD/CAM vs. hand forming).

The present study result is inconsistent with the Vojdani ${ }^{27}$ and Kim ${ }^{29}$ studies. Furthermore, in a study by Farjood, the marginal discrepancy in the conventional wax group was significantly less than that of the CAD/RP group. ${ }^{25}$ On the other hand, Nejatidanesh ${ }^{30}$ and $\mathrm{Xu}^{33}$ reported smaller marginal discrepancies in the CAD/CAM compared with conventional group which this study agrees with. $\operatorname{Han}^{26}$ reported a significant difference between marginal adaptation in $\mathrm{CAD} /$ milling hard metal and conventional wax-up group, while there was no significant difference between these two groups in the present study. Conversely, Ghodsi reported that CAD/CAM technique for wax milling led to better marginal adaptation rather than milling metal blocks, ${ }^{31}$ while this study found no significant difference between these groups.

The controversial results could be explained by the effects of different factors on the accuracy and adaptation of computer- or hand-made models. Several studies confirm that different prostheses length, ${ }^{41}$ materials, ${ }^{31,42}$ finishing line configuration, ${ }^{26,43}$ and even framework design, ${ }^{44}$ and measurement method ${ }^{31}$ could affect the accuracy obtained by different fabrication methods.

McLean and von Fraunhofer suggested that the clinically accepted marginal discrepancy is $120 \mu \mathrm{m},{ }^{45}$ which means that the conventional wax patterns' marginal adaptation in the present study was not clinically acceptable; however, the marginal discrepancies in other groups were within the acceptable range.

Evaluating the accuracy of different methods will help the clinician in finding the best method according to the related situation in this growing world of science. The present study measured vertical marginal discrepancies. However, not cementing the specimens, not subjecting the specimens to thermal cycling or aging, and not performing layering stage could be mentioned as study limitations. It is suggested to consider horizontal marginal discrepancy and measure the adaptation both before and after cementation to compare the difference and assess the effect of cementation on marginal gap.

\section{Conclusion}

Keeping in mind the limitations of this study, it can be concluded that the framework fabricated by the conventional wax-up technique had, by far, the highest marginal gap compared with the other methods. We also found that the marginal fit of framework made by the CAD/CAM soft metal method was better than the other techniques. In addition, frameworks fabricated by the RP method showed acceptable adaptation on the abutment analogs.

\section{Conflict of Interest}

None declared.

\section{Acknowledgment}

The authors would like to thank the vice-chancellor of Tehran University of Medical Sciences and Health Services, Tehran, Iran, for supporting the research.

\section{References}

1 Siadat H, Mirfazaelian A, Alikhasi M. Scanning electron microscope evaluation of marginal discrepancy of gold and base metal implant-supported prostheses with three fabrication methods. J Indian Prosthodont Soc 2008;8(3):148-153

2 de Torres EM, Rodrigues RC, de Mattos MdaG, Ribeiro RF. The effect of commercially pure titanium and alternative dental alloys on the marginal fit of one-piece cast implant frameworks. J Dent 2007;35(10):800-805

3 Katsoulis J, Mericske-Stern R, Yates DM. Izutani N, Enkling N, Blatz MB. In vitro precision of fit of computer-aided design and computer-aided manufacturing titanium and zirconium dioxide bars. Dent Mater 2013;29(9):945-953

4 Yeo IS, Yang JH, Lee JB. In vitro marginal fit of three all-ceramic crown systems. J Prosthet Dent 2003;90(5):459-464

5 Kan JY, Rungcharassaeng K, Bohsali K, Goodacre CJ, Lang BR. Clinical methods for evaluating implant framework fit. J Prosthet Dent 1999;81(1):7-13

6 Manicone PF, Rossi Iommetti P, Raffaelli L. An overview of zirconia ceramics: basic properties and clinical applications. J Dent 2007;35(11):819-826

7 Oyagüe RC, Sánchez-Turrión A, López-Lozano JF, Suárez-García MJ. Vertical discrepancy and microleakage of laser-sintered and vacuum-cast implant-supported structures luted with different cement types. J Dent 2012;40(2):123-130

8 Oyagüe RC, Turrión AS, Toledano M, Monticelli F, Osorio R. In vitro vertical misfit evaluation of cast frameworks for cement-retained implant-supported partial prostheses. J Dent 2009;37(1):52-58

9 Tabesh M, Alikhasi M, Siadat H. A comparison of implant impression precision: different materials and techniques. J Clin Exp Dent 2018;10(2):e151-e157

10 Albert FE, El-Mowafy OM. Marginal adaptation and microleakage of Procera AllCeram crowns with four cements. Int J Prosthodont 2004;17(5):529-535

11 Nawafleh NA, Mack F, Evans J, Mackay J, Hatamleh MM. Accuracy and reliability of methods to measure marginal adaptation of crowns and FDPs: a literature review. J Prosthodont 2013;22(5):419-428

12 Pettenò D, Schierano G, Bassi F, Bresciano ME, Carossa S. Comparison of marginal fit of 3 different metal-ceramic systems: an in vitro study. Int J Prosthodont 2000;13(5):405-408

13 Sulaiman F, Chai J, Jameson LM, Wozniak WT. A comparison of the marginal fit of In-Ceram, IPS Empress, and Procera crowns. Int J Prosthodont 1997;10(5):478-484

14 Good M-L, Mitchell CA, Pintado MR, Douglas WH. Quantification of all-ceramic crown margin surface profile from try-in to 1-week post-cementation. J Dent 2009;37(1):65-75

15 Abduo J. Fit of CAD/CAM implant frameworks: a comprehensive review. J Oral Implantol 2014;40(6):758-766

16 Abduo J, Lyons K, Bennani V, Waddell N, Swain M. Fit of screw-retained fixed implant frameworks fabricated by different methods: a systematic review. Int J Prosthodont 2011;24(3):207-220

17 Alikhasi M, Monzavi A, Bassir SH, Naini RB, Khosronedjad N, Keshavarz S. A comparison of precision of fit, rotational freedom, and torque loss with copy-milled zirconia and prefabricated titanium abutments. Int J Oral Maxillofac Implants 2013;28(4):996-1002 
18 Rosenstiel SF, Land MF, Contemporary Fixed Prosthodontics JF 4th ed. St. Louis: Mosby; 2006:562-579

19 Sun J, Zhang FQ. The application of rapid prototyping in prosthodontics. J Prosthodont 2012;21(8):641-644

20 Strub JR, Rekow ED, Witkowski S. Computer-aided design and fabrication of dental restorations: current systems and future possibilities. J Am Dent Assoc 2006;137(9):1289-1296

21 Witkowski S. (CAD-)/CAM in dental technology. Quintessence Dent Technol 2005;28:169-184

22 Abduo J, Lyons K, Swain M. Fit of zirconia fixed partial denture: a systematic review. J Oral Rehabil 2010;37(11):866-876

23 Tan PL, Gratton DG, Diaz-Arnold AM. Holmes DC. An in vitro comparison of vertical marginal gaps of CAD/CAM titanium and conventional cast restorations. J Prosthodont 2008;17(5):378-383

24 Miyazaki T, Hotta Y, Kunii J, Kuriyama S, Tamaki Y. A review of dental CAD/CAM: current status and future perspectives from 20 years of experience. Dent Mater J 2009;28(1):44-56

25 Farjood E, Vojdani M, Torabi K, Khaledi AA. Marginal and internal fit of metal copings fabricated with rapid prototyping and conventional waxing. J Prosthet Dent 2017;117(1):164-170

26 Han HS, Yang HS, Lim HP, Park YJ. Marginal accuracy and internal fit of machine-milled and cast titanium crowns. J Prosthet Dent 2011;106(3):191-197

27 Vojdani M, Torabi K, Farjood E, Khaledi A. Comparison the marginal and internal fit of metal copings cast from wax patterns fabricated by CAD/CAM and conventional wax up techniques. J Dent (Shiraz) 2013;14(3):118-129

28 Eftekhar Ashtiani R, Nasiri Khanlar L, Mahshid M, Moshaverinia A. Comparison of dimensional accuracy of conventionally and digitally manufactured intracoronal restorations. J Prosthet Dent 2018;119(2):233-238

29 Kim EH, Lee DH, Kwon SM, Kwon TY. A microcomputed tomography evaluation of the marginal fit of cobalt-chromium alloy copings fabricated by new manufacturing techniques and alloy systems. J Prosthet Dent 2017;117(3):393-399

30 Nejatidanesh F, Shakibamehr AH, Savabi O. Comparison of marginal and internal adaptation of CAD/CAM and conventional cement retained implant-supported single crowns. Implant Dent 2016;25(1):103-108

31 Ghodsi S, Pirmoazen S, Beyabanaki E, Rostami M, Alikhasi M. The effect of milling metal versus milling wax on implant framework retention and adaptation. J Prosthodont 2019;28(2):e739-e743

$32 \mathrm{Ng} \mathrm{J}$, Ruse D, Wyatt C. A comparison of the marginal fit of crowns fabricated with digital and conventional methods. J Prosthet Dent 2014;112(3):555-560
33 Xu D, Xiang N, Wei B. The marginal fit of selective laser melting-fabricated metal crowns: an in vitro study. J Prosthet Dent 2014;112(6):1437-1440

34 Lalande D, Hodd JA, Brousseau JS, Ramos V, Dunham D, Rueggeberg F. Marginal discrepancy dimensions of single unit metal crowns fabricated by using CAD-CAM-milled acrylate resin polymer blocks or a conventional waxing technique. J Prosthet Dent 2018;119(6):948-953

35 Nesse H, Ulstein DM, Vaage MM, Øilo M. Internal and marginal fit of cobalt-chromium fixed dental prostheses fabricated with 3 different techniques. J Prosthet Dent 2015;114(5):686-692

36 Afify A, Haney S, Verrett R, Mansueto M, Cray J, Johnson R. Marginal discrepancy of noble metal-ceramic fixed dental prosthesis frameworks fabricated by conventional and digital technologies. J Prosthet Dent 2018;119(2):307.e1-307.e7

37 Park JK, Kim HY, Kim WC, Kim JH. Evaluation of the fit of metal ceramic restorations fabricated with a pre-sintered soft alloy. J Prosthet Dent 2016;116(6):909-915

38 Zeltser C, Lewinstein I, Grajower R. Fit of crown wax patterns after removal from the die.J Prosthet Dent 1985;53(3):344-346

39 Borba M, Cesar PF, Griggs JA, Della Bona Á. Adaptation of all-ceramic fixed partial dentures. Dent Mater 2011;27(11):1119-1126

40 Moldovan O, Luthardt RG, Corcodel N, Rudolph H. Threedimensional fit of CAD/CAM-made zirconia copings. Dent Mater 2011;27(12):1273-1278

41 Akçin ET, Güncü MB, Aktaş G, Aslan Y. Effect of manufacturing techniques on the marginal and internal fit of cobalt-chromium implant-supported multiunit frameworks. J Prosthet Dent 2018;120(5):715-720

42 Arora A, Yadav A, Upadhyaya V, Jain P, Verma M. Comparison of marginal and internal adaptation of copings fabricated from three different fabrication techniques: an in vitro study. J Indian Prosthodont Soc 2018;18(2):102-107

43 Johnson R, Verrett R, Haney S, Mansueto M, Challa S. Marginal gap of milled versus cast gold restorations. J Prosthodont 2017;26(1):56-63

44 Patil A, Singh K, Sahoo S, Suvarna S, Kumar P, Singh A. Comparative assessment of marginal accuracy of grade II titanium and $\mathrm{Ni}-\mathrm{Cr}$ alloy before and after ceramic firing: An in vitro study. Eur J Dent 2013;7(3):272-277

45 McLean JW, von Fraunhofer JA. The estimation of cement film thickness by an in vivo technique. Br Dent J 1971;131(3): 107-111 